\title{
Question on Questioning Skill of Health Educators in Nepal
}

\author{
Kusum Raj Subedi ${ }^{1}$, Bhagwan Aryal ${ }^{2}$, Anup Adhikari ${ }^{*}$ \\ ${ }^{1}$ Heath Education at Shahid Smriti Multiple Campus Chitwan, Affiliated to TU, Kirtipur, Nepal \\ ${ }^{2}$ Central Department of Education, Tribhuvan University, Kirtipur, Nepal \\ ${ }^{3}$ Nepal Family Development Foundation and Hope International College, Lalitpur, Nepal \\ Email: *ecoanup@gmail.com
}

How to cite this paper: Subedi, K. R., Aryal, B., \& Adhikari, A. (2021). Question on Questioning Skill of Health Educators in Nepal. Creative Education, 12, 391-401. https://doi.org/10.4236/ce.2021.122028

Received: January 4, 2021

Accepted: February 20, 2021

Published: February 23, 2021

Copyright (c) 2021 by author(s) and Scientific Research Publishing Inc. This work is licensed under the Creative Commons Attribution International License (CC BY 4.0).

http://creativecommons.org/licenses/by/4.0/

\begin{abstract}
Health education is a behavioral science under faculty of education which includes the suffice courses on the use of questioning skills. This study was carried out to identify the knowledge of using the skill of questioning and its use in real classroom situations among health education teachers in education campuses where health education was taught at Bachelor and Master Levels. A qualitative phenomenological research design was applied to draw result. The 4 districts were selected from the Bagamati Province purposively and inclusive of geographic balance. Purposive sampling method was adopted to select teachers for in-depth interviews, classes for observation, and FGDs to assemble reliable and valid information for the study. Trustworthiness was maintained through consultation with experts, thick description, members check and credibility, and the methods triangulation was used to make data analysis rigorous. Though the sampled teachers had some pedagogical knowledge of questioning, this was insufficiently transferred into classroom instruction.
\end{abstract}

\section{Keywords}

Health Education Teaching, Prompting, Probing, Questioning Skill, Redirecting

\section{Introduction}

Teaching is a complex task. It is a set of skills for the realization of a specified set of objectives (Aggarwal, 1996). The changing role of the teacher in education has been the result of plurality of intertwining influences, philosophical, psychological, social, technological, and educational (Popkewitz, 2011). The shift in emphasis from the teacher to the pupil as the central figure in the process of educa- 
tion and the merge of instructional activities with the realization of specific and clear-cut learning outcomes has inevitably led to a reassessment of the teacher's role in the classroom. Questioning is a major technique to draw the attention of students and evaluate the students' understanding of the lesson or subject matter (Angelo \& Cross, 2012). This method also helps the students to know how far they have been able to grasp the idea or subject matter (McPeck, 2016).

A question is any sentence that has an interrogative form or function (Kuno, 1972). In classroom settings, teacher questions are defined as instructional cues or stimuli that convey to students the content elements to be learned and directions for what they are to do and how they are to do it. Effective questioning challenges students and teachers to use good questions as a way to open conversations and further academic inquiry (Michaelson, 2002). Effective questioning depends on classroom conversation and the level of discourse students apply to their work. Teachers use this strategy to create opportunities for students to investigate and analyze their thinking as well as the thinking of their peers and the authors that they read in each of their classes (Slavin, 2019).

Questions are generally of three types: 1) Lower order, 2) Middle-order, 3) Higher-order, and each type has its functions as well as merits. However, for college students, higher-order questions will be more relevant, as these could result in the development of the most desirable aspects of the cognitive domain. Lower order questions are those questions that merely test the ability to recall. Middle-order questions test the grasp of the subject and the ability to apply it. Questions that require interpretations and application of ideas, citation of examples, extrapolation, procedural sequence, etc. come under middle-order questions and these too can be encouraged in college classes.

Higher-order questions can develop higher mental abilities like analysis, synthesis, evaluation, and creativity and increase critical awareness (Varma \& Vedanayagam, 2007). These questions generally take the shape of "why" or "how". The answers given by the students may be 1) correct, 2) completely wrong, 3) one part correctly answered, 4) partially right or partially wrong.

Hargie refers to two types of sequencing during questioning, "funnel sequencing" (open-to-closed) and "inverted funnel sequencing" (closed-to-open). The former is considered useful when the questioner wishes to begin by openly addressing broader issues before gradually addressing more factual ones (Hargie, 2010).

In comparison, inverted funnel sequencing begins with closed questions, gradually expanding out into a more open questioning strategy. Being an inclusive strategy, this approach should help stimulate participation at an early stage in proceedings while improving confidence across the student group.

The questioning form is a vital part of teaching and learning and is especially important in promoting discussion, interaction, and critical thinking during class (Jonassen, Davidson, Collins, Campbell, \& Haag, 1995). There are two main types of questions: open-process and closed. While the former is used to promote discussion and critical thinking, the latter helps to develop factual recall 
(cognitive set) and remembering. Closed questions are also considered beneficial in encouraging all learners to respond. Open questions resemble the higher levels of Bloom's Taxonomy and are necessary if the number of closed questions is to be reduced (Tofade, Elsner, \& Haines, 2013). Tofade, Elsner, and Haines (2013) further say that open, or higher-order, questions may be pre-planned and is a useful strategy in promoting deep understanding as opposed to surface learning (Tofade et al., 2013).

A teacher's questioning technique should associate with enhanced achievement. Besides, it should include a balance of Convergent or related and divergent or contrary questions, probing questions, listening to student responses, redirecting student responses to other students, providing respectful feedback, and allowing for an appropriate time after asking a question (Wood \& Anderson, 2001).

The greatest attribute of questioning is that it stimulates thinking in the classroom (Filippone, 1998). Research indicates that almost forty percent of classroom time is spent in a question-response mode (Johnston, Markle, \& Haley-Oliphant, 1987).

Questioning is, in fact, the most important teaching technique. Although it is highly praised in teaching-learning, many teachers do not ask questions effectively (Gall, 1984). Ineffective or inappropriate practices include asking questions at only lower cognitive levels (Ornstein, 1987), directing a disproportionate percentage of questions toward a limited number of students (Jones, 1990), or waiting only for a short time after asking a question and before reacting to the student's response-typically one second or less (Rowe, 1986). Teachers are likely to ask at least fifty questions during a typical class period while it is unlikely that the students in the class ask even one question (Barnette, 1994).

Roth considers questions as an important form of instructional interaction as they act as motivational stimuli and have arousal and associative outcomes. By asking questions, the teacher can construct students thinking and ways of inquiry (Roth, 1996). Stevens states that approximately eighty percent of a teacher's time that is eighty-three days is spent asking questions directed towards their students (Stevens, 1912). More contemporary research on teacher questioning behaviors and patterns indicate that this trend has not been changed. Teachers ask between three hundred to four hundred questions each day (Brualdi, 1998).

The teachers may use the techniques of prompting, probing, and redirecting and thus follow up the questions (Allen, Cooper, \& Poliakoff, 1972):

1) Prompting: The question can be broken up into parts where the initial question is difficult to answer. Further clues or hints may be given for the students to complete.

2) Probing: When the initial response by the student is incomplete or partially correct, questions requiring the student to clarify elaborate, or explain his/her initial answer may be asked. A student may further be questioned on a correct answer for relating it to another similar situation and thus help the student to 
view the response in a broader perspective. The student may be helped in his reasoning by asking "how" when the initial question is answered correctly.

3) Redirecting: A discussion can be stimulated among the students by asking other students to answer the same or addressing it to the class in general. The redirecting technique increases the student's participation. As we have seen, different types of questions are asked to make the students exercise their power of recall and recognition, exercise their reasoning ability, reflect over things and ideas, compare and contrast things or help and initiate the students to a discussion.

The major goal of any teacher education program is to provide teachers with the essential knowledge and skills required for effective teaching. The health education curriculum at Tribhuvan University (TU) aims to produce quality teacher and teacher educator in the field of health education. The courses include both content and pedagogical skills. Such skills are practiced in the micro-teaching programs too. However, the health education teachers after the end of their degree find it hard to implement the knowledge and skills received from the courses.

Graduate education faculty are called the trained ones in Nepal. Nevertheless, they are not able to practice or they do not practice trained skills in their respective institutions. Despite the emphasis on teacher training, and regardless of the growing literature on teacher preparation and training research, this area has remained a subject of criticism for failing to prepare quality teachers adequately in Nepal.

Health education is a behavioral science to promote health awareness. It also includes sensitive and delicate contents. Health education teachers must be thoroughly acquainted with the knowledge and skill of opening a class effectively. How teachers transmit information and go about the lesson is an important area of inquiry that could lead to the improvement of education (Eisner, 2017). Although TU health education courses focus on linking knowledge and skills for teaching by using various psychological and educational approaches of questioning, the real classroom practice is still perceived as less effective.

\section{Materials and Methods}

This study used a qualitative phenomenology method. It incorporated all the health education teachers teaching at bachelor and master levels at different campuses affiliated to TU in Bagamati Province of Nepal. Sample campuses and teachers from 4 districts of 3 geographical regions (Mountain-Dolakha, Hill-Kathmandu and Bhaktapur, and Terai-Chitwan) were selected purposively and inclusive of geographic balance. Eighteen teachers were interviewed in-depth and 19 teachers' classroom instructions were observed, whereas 4 Focus Group Discussions (FGDs) were conducted. Twenty-six teachers participated in the FGDs. However, the teachers who were teaching on two or more campuses were included only once as a sample in the study. 
An in-depth interview guideline was used to collect data related to teachers' knowledge of using the skill of questioning. As for the class observation, an observation guideline of different teaching skills including the use of questioning was used. It explored the competency of the trained teachers if they demonstrated the skill in a classroom while asking questions. An FGD topic guide was used to dig deeper into the situation and perceived causes of not using the skill.

The trustworthiness of the tools was maintained through consultation with experts, thick description, members check, and triangulation. Thematic interpretation and analyses were interwoven from various datasets for triangulation. Participants were informed about the study objective, risk, and benefit of the study, and verbal consent was taken and requested for voluntary participation. Information obtained from participants was kept confidential with anonymity. Participants were given the right to quit at any time of data collection. Concerning the cultural and social norms of participants were paid attention to throughout the research process.

\section{Results and Discussion}

\subsection{Knowledge of Questioning Skill among Health Education Teachers}

The skill of questioning was understood as asking questions by the teachers; however, they linked it to motivation again. Many teachers in FGDs and In-depth Interviews said, "Skill of questioning means creating an environment that motivates the learners to express their learning outcomes". Another teacher from Chitwan also defined it wrongly as "the means to present the topics to the students in the way they can understand". One of the teachers in Kathmandu said that he forgot the exact meaning of questioning and its components, he used it in the classroom occasionally. Defining the meaning, giving an introduction, or illustrating was difficult for most of them.

However, a teacher who had twenty-four years of teaching experience said that it is the process of finding whether students have understood the subject matter or not through some long, short, or prompt type questions. A female teacher in Bhaktapur and a male teacher in Kathmandu were very confirmed that it is to expose the students' level of understanding which can be achieved either by short or long questions. One of the teachers said it was an instrument designed to understand the purpose of the lesson and to fulfill the purpose. He also said that it is an art of presenting questions that support the students to understand the lessons taught in the classroom.

When it was asked them about what activities are done under the skill of questioning, teachers gave the following answers:

"Students are questioned at the end of the lesson. It involves the skill of prompting, probing, etc." (a lecturer in Bhaktapur).

"Questioning skill includes short or long questions or some hints related to the topic" (a lecturer in Bhaktapur). 
"Asking short questions and letting the students answer and then forming more questions from their answers" (a lecturer in Chitwan).

"Letting students revise the concept of what has been taught and involving them in oral practice" (a lecturer in Chitwan).

"Skill of questioning generally includes short questions for prompting, probing and redirecting purpose" (a lecturer in Kathmandu).

"Questioning must be simple enough to eliminate the student's fear. They should be asked simple questions after guessing their understanding level" (a lecturer in Chitwan).

In conclusion, teachers represented a normal understanding of the skill of questioning. Some of the teachers could not define it although they use this skill. Some others defined it correctly but linked it again as an ingredient of motivation. On asking specifically, what is done under prompting, probing, and redirecting, then only most of them remembered and illustrated well. It shows that these teachers studied the skills in their college but forgot a lot after not studying and practice further.

\subsection{Application of Questioning Skill in Instruction}

While using the skill of questioning, a teacher can use the techniques of prompting, probing, and redirecting and thus follow up the questions (Allen \& Ryan, 1969). It was asked the teachers how did they ask questions to their students and how did they use a specific skill under it.

Some of the teachers took it as a tool for evaluating student at the end of the lesson (e.g., a teacher in Bhaktapur) however, some others from Chitwan, Dolakha, Kathmandu, and Bhaktapur said they used verbal questions, by giving hint, dividing the main question into pieces, circulating the question to many students and asking very short questions at the middle as well as the end of the lesson. Although many of them could not define it, they applied the skills of prompting, probing, and redirecting when needed.

A teacher from Chitwan said that a speaker can materialize questioning skills verbally, or by hinting or writing too. He further said, "Most of the teachers use a verbal method of questioning, but I provide the students numerous questions and they discuss on them and prepare a report and submit their report collectively." He said when students did not understand the question, it was further divided into pieces and when they felt difficulty, they were given clues. He also used the split questions as per the requirement. According to him, he employed them in exploring the answer and sometimes used the re-directing method as per the need.

On the other hand, a male teacher with twenty-four-year experience from Bhaktapur and a male teacher with twenty-year experience from Chitwan added that the students of bachelor and master level do not prefer to be asked such questions, so at this level, the questioning is rarely used. It was found in FGDs in Kathmandu and Chitwan where some teachers said that it is rather important to 
proceed with the course and explain the things to them than rather asking questions because no one will answer anything. "The level of understanding and interacting is too poor among the students, so better not to ask the question during the process of explanation. I ask them questions at the start to link the lesson and finish it' (a teacher in FGD in Chitwan).

One of the senior teachers from Dolakha who was fifty-six years old also raised the issue of using this skill in the classrooms tactfully. He said, "Some students become unable to answer even if they have understood or grasped the idea. Questions are the tools to be used carefully. Otherwise, it hurts the students and they become discouraged to learn". He used to choose the questions and create an environment for their response. He said that the students could also make many questions that can be exchanged between and among them supported by him if any difficulties arose.

In the observation of a class in Bhaktapur, It was found that the teacher was asking questions to the students; however, the students did not understand his question. They could not reply answer. He did not make students clear about the question and ignored them. A female teacher in Bhaktapur asked no questions at all to the students.

Interestingly, the teachers of Kathmandu and Chitwan asked smaller questions in between and at the end of the lesson to the students. It was seen that this bound the students to the lesson. Some teachers in Kathmandu asked questions and did not clarify the questions further. It was found asking questions to some extent by all the teachers, but the right use of prompting, probing, and redirecting skills was seen less. Asking objective type and very short questions were in practice among the teachers.

Questioning in teaching and learning is frequently taken for granted, but it is a skill that needs conscious development if we are to become effective teachers (Scales \& Kelly, 2012). Constructivist theory suggests that students construct knowledge and meaning from their experiences. Learner falsifies, constructs, and reconstructs knowledge by himself/herself. Learners are considered to be active organisms seeking meaning through action and interaction. Therefore, teachers should pose appropriate questions related to the course and allow students to find out the possible solutions through interaction as proposed by constructivists. When they could not find an appropriate solution to the posed problem then teachers or more knowledgeable others should scaffold their learning.

A teacher's questioning technique, correlating with enhanced achievement, should include a balance of convergent and divergent questions, probing questions, listening to student responses, redirecting student responses to other students, providing respectful feedback, and allowing for an appropriate time after asking a question. Convergent questions serve the purpose of getting low-level cognitive information from students; divergent or open-ended questions are more likely to stimulate a discussion and foster an interactive and democratic classroom atmosphere (Wragg, 1989).

Sometimes it is perceived that the questions too often flow in only one direc- 
tion and become a way of maintaining control rather than stimulating thought. It is observed in many instances that Nepalese teachers ask questions for just questioning, and in real classroom situations, they exhibit very less skills of prompting, probing, and redirecting the questions. For example, Aryal and Adhikari found that more than 60 percent of teachers of Bachelor level campuses in Kathmandu defined what is questioning skill well; but in observations of their classes, 42 percent of teachers did not use prompting, 75 percent of them did not use probing, and 67 percent of them did not use redirecting skills while questioning (Aryal \& Adhikari, 2019).

The practice of questioning skills among health education teachers is based on verbal short questions, usually at the end of the lesson but prompting, probing, and redirecting skills are not deliberately carried. Questions are asked for the sake of questioning; however, this is also in a decreasing trend. Teachers believe that asking questions to the students of higher level is not necessary because students do not like interactions and are not responsive.

There are six question categories (Bloom \& Englehart, 2011): Knowledge, Understanding, Application, Analysis, Synthesis, and Evaluation. Teachers tend to ask questions in the "knowledge" category about eighty percent (80\%) to ninety percent $(90 \%)$ of the time. They try to utilize a higher order level of questions that require much more "brainpower" and a more extensive comprehensive and elaborate answer.

Questioning is the strongest tool at a teacher's disposal as it teaches students how to think. Teachers ask hundreds of questions every day many of which are concerned with a recall of textbook information; few questions require students to think beyond a level of recall (Arslan, 2006). Some questions are designed to clarify matters of classroom procedure. Questioning is naturally a two-sided affair. Not only is it that teachers put forth questions but equally students are involved in the process through the responses they offer. The methods are various for effective questioning such as structuring pitching, putting forward ideas clearly and concisely, directing and distributing, posing and pacing, prompting and probing, listening to replies and responding, and sequencing.

A question is any sentence that has an interrogative form or function. In classroom settings, questions asked by teachers' are defined as instructional cues or stimuli that convey to students the content elements to be learned and directions for what they are to do and how they are to do it (Cotton, 1988).

The skill of questioning is related to asking the questions to students for evaluation of their progress, to identify the effectiveness of teaching, and to hold the students in learning. This is not merely asking a few questions at the end of the lesson, but a continuous effort of making class effective by using the techniques of prompting, probing, and redirecting (Allen et al., 1972).

\section{Conclusion and Implications}

Questioning is a powerful device of teaching. Through this device, the teacher 
transacts a lot of learning experiences. It is essentially a teacher-controlled device for promoting through making appraisals and moving students towards desired goals. However, the effective use of this skill is questioned among health education teachers in Nepal. This is only taken as a motivation ingredient by health education teachers. Many of them understand it as the process of asking questions; however, how to ask questions to students is not a simple question to them. In this context, health education teachers, in general, ask a few short questions during their instruction in the classrooms; however, they do not readily do it and show intents to drop this skill.

The health education curriculums of master and bachelor levels at TU are either more content-oriented than the pedagogy or the instructional techniques used; there is more content-focused than the pedagogical implications. This is leading to produce aspiring teachers with fewer skills of teaching such as the skill of questioning. A competent teacher must be equipped with appropriate skills of asking questions. Curricular contents must be focused on these regarding health education instructions. Moreover, appropriate opportunities for practicing these skills during course teachings must be created for aspiring teachers.

\section{Acknowledgements}

The authors would like to thank the Faculty of Education, Tribhuvan University for accepting this research. In this process, the advisor of this work Prof. Dr. Ram Krishna Maharjan is paid due respect and gratitude for his generous support and critical comments. Dean of Faculty of Education Prof. Dr. Krishna Prasad Gautam and Prof. Dr. Bhimsen Devkota are also acknowledged. Our gratitude goes to the participant teachers who participated in this study and the campuses which permitted data collection.

\section{Author Contributions}

KRS conceptualized and conducted the study. KRS and BA analyzed data and prepared a draft. BA and AA edited the manuscript and participated in revision. All the authors did agree to submit this paper for publication.

\section{Conflicts of Interest}

The authors declare that there is no conflict of interest in this research. The advisor of the work also gave us permission for the publication.

\section{References}

Aggarwal, J. (1996). Essentials of Educational Technology. New Delhi: Vikas Publishing House.

Allen, D. W., \& Ryan, K. (1969). Microteaching. https://archive.org/details/microteaching0000unse

Allen, D. W., Cooper, J. M., \& Poliakoff, L. (1972). Microteaching. Washington DC: US Department of Health, Education, and Welfare, Office of Education. 
Angelo, T. A., \& Cross, K. P. (2012). Classroom Assessment Techniques. Hoboken, NJ: Jossey Bass Wiley.

Arslan, M. (2006). The Role of Questioning in the Classroom. Hasan Ali Yücel Eğitim Fakültesi Dergisi, 2, 81-103.

Aryal, B., \& Adhikari, A. (2019). Cognitive Dissonance among Health Educators Due to Gap in Knowledge and Practice of Teaching Skills in Kathmandu. IJNTR, 16, 16.17-41.17. https://doi.org/10.31871/IJNTR.5.6.3

Barnette, J. (1994). Evaluation of Teacher Classroom Questioning Behaviors. Washington DC: Office of Educational Research and Improvement (ED).

Bloom, B., \& Englehart, M. (2011). Furst, E., Hill, W., \& Krathwohl, D. (1956). Taxonomy of Educational Objectives: The Classification of Educational Goals. Handbook I: Cognitive Domain. New York, Toronto: Longmans, Green.

Brualdi, A. (1998). Classroom Questions, ERIC Clearinghouse on Assessment and Evaluation. ERIC Document Reproduction, 479, 391. https://doi.org/10.7275/05rc-jd18

Cotton, K. (1988). Classroom Questioning. School Improvement Research Series, 5, 1-22.

Eisner, E. W. (2017). The Enlightened Eye: Qualitative Inquiry and the Enhancement of Educational Practice. New York, NY: Teachers College Press.

Filippone, M. (1998). Questioning at the Elementary Level. Masters Theses, Union and Hillside, NJ: Kean University.

Gall, M. (1984). Synthesis of Research on Teachers' Questioning. Educational Leadership, 42, 40-47.

Hargie, O. (2010). Skilled Interpersonal Communication: Research, Theory and Practice. London: Routledge. https://doi.org/10.4324/9780203833919

Johnston, J. H., Markle, G. C., \& Haley-Oliphant, A. (1987). WHAT RESEARCH SAYS:-About Questioning in the Classroom: Questions about Questions Are Difficult to Answer. Middle School Journal, 18, 29-33.

https://doi.org/10.1080/00940771.1987.11494749

Jonassen, D., Davidson, M., Collins, M., Campbell, J., \& Haag, B. B. (1995). Constructivism and Computer-Mediated Communication in Distance Education. American Journal of Distance Education, 9, 7-26.

https://doi.org/10.1080/08923649509526885

Jones, M. G. (1990). Action Zone Theory, Target Students and Science Classroom Interactions. Journal of Research in Science Teaching, 27, 651-660.

https://doi.org/10.1002/tea.3660270705

Kuno, S. (1972). Functional Sentence Perspective: A Case Study from Japanese and English. Linguistic Inquiry, 3, 269-320.

McPeck, J. E. (2016). Critical Thinking and Education. London: Routledge. https://doi.org/10.4324/9781315463698

Michaelson, R. (2002). Re-Thinking Laurillard: Universities, Learning and Technology. International Journal of Management Education, 2, 15-29.

Ornstein, A. C. (1987). Questioning: The Essence of Good Teaching. NASSP Bulletin, 71, 71-79. https://doi.org/10.1177\%2F019263658707149915

Popkewitz, T. S. (2011). Paradigm and Ideology in Educational Research: The Social Functions of the Intellectual (Vol. 191). London: Routledge. https://doi.org/10.4324/9780203127957

Roth, W. M. (1996). Teacher Questioning in an Open-Inquiry Learning Environment: 
Interactions of Context, Content, and Student Responses. Journal of Research in Science Teaching, 33, 709-736.

https://doi.org/10.1002/(SICI)1098-2736(199609)33:7\%3C709::AID-TEA2\%3E3.0.CO;2 $-\mathrm{R}$

Rowe, M. B. (1986). Wait Time: Slowing Down May Be a Way of Speeding Up! Journal of Teacher Education, 37, 43-50. https://doi.org/10.1177\%2F002248718603700110

Scales, P., \& Kelly, S. P. (2012). Teaching in the Lifelong Learning Sector. New York, NY: Open University Press.

Slavin, R. E. (2019). Educational Psychology: Theory and Practice. London: Pearson.

Stevens, R. (1912). The Question as a Measure of Efficiency in Instruction: A Critical Study of Class-Room Practice. New York City, NY: Teachers College, Columbia University.

Tofade, T., Elsner, J., \& Haines, S. T. (2013). Best Practice Strategies for Effective Use of Questions as a Teaching Tool. American Journal of Pharmaceutical Education, 77, 155. https://doi.org/10.5688/ajpe777155

Varma, O. P., \& Vedanayagam, E. G. (2007). Geography Teaching. Greater Noida: Sterling Publishers Pvt. Ltd.

Wood, A. T., \& Anderson, C. H. (2001). The Case Study Method: Critical Thinking Enhanced by Effective Teacher Questioning Skills. Paper Presented at the Annual International Conference of the World Association for Case Method Research \& Application, Lund, 17-20 June 2001.

Wragg, E. C. (1989). Classroom Teaching Skills: The Research Findings of the Teacher Education Project. East Sussex: Psychology Press. 